\title{
A violência na educação formal
}

\author{
Regina Maria Leme Lopes Carvalho ${ }^{1}$ \\ Pontifícia Universidade Católica de Campinas
}

\begin{abstract}
Resumo
Neste trabalho procura-se examinar aspectos da violência que ocorre nas escolas, partindo do ponto de vista da Psicanálise. São apresentados os principais pontos de vista freudianos e kleinianos para a compreensão da gênese da violência na espécie humana. Examinam-se também, as principais causas que, na escola, gerariam e manteriam situações de violência. São apresentadas algumas idéias ericksonianos e de psicólogos escolares americanos. Conclui-se dizendo que tanto a Psicanálise quanto a Sociedade dirão sim aos programas escolares que possam conter, manter e ajudar o desenvolvimento da criatividade e bem-estar em crianças e adolescentes, criando assim, um espaço de aprendizagem e desenvolvimento de cidadania.
\end{abstract}

Palavras chaves: violência na escola; psicanálise e violência.

\section{The violence in Formal Education}

\section{Summary}

ln this paper we examine some aspects of the violence in the human being, from the psychoanalytical point ofview, starting with the revision of some of freudian' s and kleinian' s ideas ofhow violence occurs. Our foccus is the violence in schools and some ideas ericksonian and other school psychologists are taken in examination. We conclude saying that, not only Psychoanalysis but all the society will say yes to the school program that can hold, mantain and help the development of creativity and good will, in children and adolescents, thus creating an espace of leaming and development of citizenship.

Key words: School violence; Psychoanalysis and violence.

Neste trabalho pretende-se analisar, se acontece e como acontece, a violência nos ambientes de educação formal, partindo do ponto de vista da Psicanálise. O que esta tem a dizer ao examinar essa questão na escola de hoje?

Entende-se por Educação formal, aquela que se dá nas instituições sociais voltadas para a educação de crianças e jovens, principalmente, normalmente chamadas Escolas e Universidades. Por oposição, Educação informal seria a das famílias, das ruas e praças, a dos amigos, clubes, trabalho, recreio das escolas etc.

Antecipando as nossas conclusões, penso que a Psicanálise diria sim à Escola na medida em que esta fosse um espaço de pesquisa e criatividade, além de transmitir os valores humanos inerentes à conquista da liberdade, autonomia e responsabilidade. Diria não quando o dogmatismo, a coerção, a repetição de conteúdo aliados a valores mercantilistas se sobressaíssem.

Educar diz respeito a um "processo de desenvolvimento da capacidade física, intelectual e moral da criança e do ser humano em geral" (Ferre ira, 1986). Assim, educação diz respeito a processos dinâmicos que visam a modificação do sujeito ao qual eles se aplicam, sujeito esse que traz em si o germe dessa própria modificação, sob a forma de potencialidades. Vista desse ângulo, a

\footnotetext{
1 Rua Sta. Mônica, no. 20, Bairro Jardim Sta. Marcelina, CEP: 13.094-531, Campinas - S.P., Fone: (OXXI9) 251-5027. FAX: (OXXJ9) 294-2113 Email: acarvalho@dglnetcom.br
} 
educação pressupõe como objeto e sujeito do processo, o próprio educando, aquele que promove e se beneficia do processo educacional. A Educação é um sf.: "l-Ato ou efeito de educar (se)", in Ferreira, 1986. É interessante abordar-se o assunto pelo lado da semântica, ou seja, dos significados que a palavra traz, porque vemos que, em primeira instância, não está implicado no conceito, um outro sujeito - o educador - mas sim a pressuposição de um processo íntimo que se desenrola no próprio sujeito: educar-se.

\section{Contribuições da Psicanálise}

O vértice comum ao pensamento de Freud e de outros psicanalistas que se ocupam de infância, mostra que os processos psíquicos que levam ao desenvolvimento, operam na mente de cada sujeito, mesmo quando são mediados ou facilitados por outra mente, como por exemplo, a da mãe. Na verdade, todas as aquisições psíquicas importantes das etapas iniciais da vida dão-se no seio da díade mãe $\mathrm{x}$ bebê. Holding, revêrie, continência, cuidados matemos, seio bom, são formas de destacar a importância do ambiente protetor e facilitador, para que haja desenvolvimento nas etapas iniciais da vida humana. Entretanto, apesar de sempre estarem implicados no desenvolvimento um do outro, mãe e bebê têm mentes separadas, que seguem o seu próprio curso, cabendo à mãe proporcionar condições para que o bebê vá entrando em contato com a sua realidade interna.

Desejos, sentimentos, fantasias e defesas, assim como limites e adequações ao real são, em primeiro lugar, vividos no "seio da mãe". A expressão vernácula "no seio da família" sugere bem essa situação de proteção, identificação, espaço de desenvolvimento. Mas, esse seio precisa ser sugado e é o bebê quem o faz. Freud dá ao bebê essa responsabilidade, tomando-o pOlia voz da herança de toda a humanidade, além das suas próprias características individuais. "A filogênese repete a ontogênese" segundo ele. Cabe ao ser humano, no decurso do seu desenvolvimento, passar por estágios ou fases, que configurariam formas diferentes de organização da libido e que determinariam as condições de contato com o mundo interno e externo. Duas formas principais presidem a essa organização: na primeira, ou na do princípio primário, há a supremacia do princípio do prazer sobre o da realidade. Na segunda, ou na do princípio secundário, ocorre o contrário. Uma mente que funcione segundo o princípio do prazer, é aquela na qual os desejos devem ser imediatamente realizados, a frustração não é suportada, mas veementemente expelida "para fora" e as fantasias de onipotência e controle predominam. Klein (1932/ Psicanálise da Criança) explicita que, ao funcionar segundo essas características, a mente vive em contrapartida, intensos sentimentos e fantasias de medo e aniquilação, porque o mundo externo é vivido como se tivesse ficado tão perseguidor quanto as fantasias que para ele foram expelidas. Ela diz "Entre os fatores que são de importância fundamental para a dinâmica dos processos psíquicos, sou de opinião que devemos colocar não somente a polaridade, mas também a interação dos instintos de vida e de morte. Existe um vínculo indissolvível entre a libido e as tendências destrutivas, que coloca a primeira, em larga escala, em poder das últimas". (p. 204, 205). Por causa dessa situação, a mente imatura não consegue estabelecer com a realidade externa (porque também não o faz com a interna) uma relação de troca satisfatória; apenas é possível uma relação de domínio x submissão. São momentos em que a polaridade emocional é a mais intensa. Amor e Ódio ficam separados e promovem fantasias de situações idealmente sublimes e magníficas ou aterrorizadoras e aniquiladoras. Tanto Freud quanto Melanie Klein, mostram que as vivências emocionais nessas formas de organização mental são 
violentas. Por isso para a Psicanálise, uma das formas de se pensar a violência é ligando-a àqueles estados primitivos de mente, nos quais a forma de organização mental promove as vivências acima descritas. A violência passa a ser vista de dois ângulos diferentes: o do ataque e o da defesa.

Freud (1919,1940[1938]) acha que a violência, referida por muitos adultos e que, na maioria das vezes é vivida só na fantasia, tem origem em desvios e transformações da libido para ocultar desejos e prazeres libidinosos que são - agora que a mente funciona segundo as normas do princípio secundário, ou seja, segundo o primado da realidade - considerados proibidos. "Acredito que essas fantasias primitivas (sedução de crianças, espancamentos, ameaças de castração), como prefiro denominá-las,... constituem um acervo filogenético,... foram em determinadas épocas ocorrências reais dos tempos primitivos da família humana. "(p.433). Aponta para uma penosa luta que o Ego infantil, imaturo e fraco trava com os seus impulsos e as forças repressoras do Super Ego e da realidade, o que cria muitas tensões que vão se refletir na sua vida de adulto. "Impulsionado pela operação combinada dessas duas influências, o perigo real e presente e o perigo relembrado com sua base filogenética, a criança embarca em suas tentativas de defesa - repressões - que são momentaneamente eficazes mas que, todavia, se tornam psicologicamente inadequadas quando a reanimação posterior da vida sexual traz reforços às exigências instintivas que haviam sido repudiadas no passado". Mais adiante diz: "E, nesse ponto, podemos antecipar a tese de que muitos bens altamente valorizados da nossa civilização foram adquiridos à custa da sexualidade e através das forças motivadoras sexuais ". (pp229 - 23 O, Esboço de Psicanálise).

Em síntese, poderíamos dizer que, para Freud, violência e civilização têm o mesmo berço. O destino de cada indivíduo depende de como ele pode usar, ou interpretar, a sua herança, seus aspectos constitucionais e as características do ambiente.

Melanie Klein e Bion, entre outros psicanalistas, tendem a dar uma maior ênfase à conjunção pessoa x ambiente, como fontes de vida e desenvolvimento. Há em Bion um espaço para a filogênese e em Klein um outro para a constituição, mas esses espaços serão diversamente povoados seja de tumulto, seja de construtividade, dependendo da qualidade do ambiente. Assim, a violência do ódio, da inveja e da onipotência pode ser matizada por um ambiente amoroso, cuidador e cooperador, verdadeiro e real.

Klein (1932/ Psicanálise da Criança), enfatiza a importância de se observar certos aspectos do desenvolvimento da libido que estariam ligados a maior incidência da inveja e do ódio nas fazes anal e fálica. Quando as forças do sadismo anal são muito intensas produz-se um ataque generalizado aos vínculos do amor e conhecimento que estão na base dos processos de desenvolvimento. Klein (1921) considerou tão importante e fundamental o impulso para o conhecimento, que lhe deu o status de instinto instinto epistemofílico. Corroborando as bases sexuais dos impulsos para o conhecimento e o desenvolvimento, Melanie Klein em 1931, em seu artigo sobre "The theory ofintellectual inhibition" (p. 243), acrescenta que essa linha de interpretações nos aclara quanto as causas que estão na base da polêmica entre o instinto sexual e o instinto de conhecimento (epistemofílico), já que no inconsciente, descobrir e penetrar nas coisas são atividades correlatas. Mas, se o ego infantil, não pode tolerar frustração e se desorganiza, passa a ter uma grande dificuldade em conviver com aspectos de espera e contenção, de partilha e de construção. Klein, como Freud, dá uma importância muito grande a essas forças instintivas que, sendo em parte constitucionais, podem também ser trabalhadas pelas forças ambientais. Neste particular, Klein salienta o papel da relação mãe x filho valorizando a qualidade da relação, 
qualidade esta que pode ser de amor e construção ou de ódio e desestruturação.

Bion (1962-3), entre outros aspectos da sua teoria, retoma e desenvolve a importância da relação entre o sujeito e seus objetos, propondo a sua teoria dos vínculos. Segundo ele, as nossas relações de objeto podem se dar fazendo prevalecer ora o vínculo de amor (L), ora o de ódio (H), ou ainda o de conhecimento (K). Cada um desses vínculos pode ser visto de uma forma positiva ou negativa ( $\mathrm{L}+$ ou L-; H+ ou H-; K+ ou K-) conforme prevaleçam a construção ou a destrutividade.

A brevíssima revisão desses postulados da Psicanálise tem por motivo, criar um alicerce teórico conceitual sobre o qual será possível desenvolver alguns argumentos a respeito da violência na educação formal. Entretanto, vale a pena acrescentar outros aspectos como o pensamento de Erikson, psicanalista que teve grande influência nos terrenos da educação, principalmente da adolescência. Creio que é útil mencionar aqui, algumas de suas idéias que poderão servir de ponte entre os postulados da Psicanálise clássica e algumas realizações concretas no âmbito da educação formal.

Como os psicanalistas já citados, Erikson (1976) também se apóia na idéia de que há uma dupla contribuição da parte inata e da adquirida na composição da organização psíquica e que esta se desenvolve ao longo de estágios seqüenciais. O interessante é que ele acrescenta algumas idéias às fases do desenvolvimento da libido de Freud. Nomeia para cada estágio um conflito próprio e inerente e uma virtude que se desenvolverá da passagem de um estágio para o outro. Apontaremos apenas aqueles estágios que servirão para dar prosseguimento à nossa discussão. Assim, para o primeiro estágio que ele chama de "incorporativo " e que transcenderia a fase oral de Freud, o conflito é o da confiança $x$ desconfiança e a criança ao lidar com ele deverá adquirir a virtude da fé, que a ajudará a construir o próximo estágio. O segundo estágio (que corresponderia à fase anal) é o da fase retentiva x expulsiva, na qual os impulsos contraditórios são os de "agarrar x soltar", "deter $x$ deixar ir ", e o conflito é o de autonomia $x$ vergonha e dúvida. O ambiente precisa apoiar e fortalecer a autonomia da criança para que ela possa passar adiante, tendo adquirido "o poder da vontade e o sentimento de justiça", que têm no princípio da "lei e da ordem", a sua representação constitucional $(\mathrm{s} / \mathrm{n})$. No terceiro estágio, correspondente à fase fálica freudiana, há uma oposição entre "jálico x castrado" e entre "intrusão x submissão ". É o momento em que se inicia a oposição masculino/feminino que irá se finalizar na adolescência, quando é possível a reedição dos conflitos gerados pela oposição de "iniciativa x culpa". Erikson diz que na vida essas posições se misturam: ativo/passivo, positivo/negativo. A criança que finaliza esse terceiro período da vida, descortina os horizontes éticos e estéticos da cultura. A virtude obtida desse período é a "determinação ", a qual permite o despontar de um "sentimento moral", de uma "ética da ação", que insere a criança na realidade concreta da civilização. No quinto estágio (latência freudiana), cessaria a dependência total da criança em relação aos pais. O trabalho escolar e a atividade em grupo passam a constituir o centro da vida da criança, transpondo-a para além da família. O conflito instalado é o da "aprendizagem x paralisia operacional", ou seja, o da ambivalência entre compartilhar ou encastelar-se . A virtude advinda desse período é a da "competência".

Em resumo, segundo Erikson as crianças ao chegarem à fase de educação formal (latência), já poderiam ter condições de lidar com "virtudes", ou seja, estados de mente fundamentais para a convivência social e o desenvolvimento social. São eles: a fé, o poder da vontade e o sentimento de justiça, o princípio da lei e da ordem, a determinação e a ética da ação e finalmente, a competência. Sim, mas para que uma criança possa desabrochar dessa forma é preciso que mundo interno 
(capacidades constitucionais e herdadas) e mundo externo (relações mãe, pai, filho e sociedade) se dêem as mãos. Não creio que seja difícil encontrarem-se crianças, vindas de um bom ambiente familiar, que apresentem tais condições ao entrar na escola. O mais difícil, nos dias de hoje, é encontrar uma escola em condições de se preocupar com o desenvolvimento de tais qualidades.

\section{Contribuições da Psicologia e da Educação}

II - Estamos assistindo no Brasil, neste fim de século, uma retomada do interesse pela educação. Mais do que isso, investir em educação tornou-se uma prioridade nacional. Pode parecer estranho dizer isso num fórum internacional, mas quem conhece a realidade brasileira, sabe os percalços pelos quais a educação do povo, vista do seu ponto de vista mais amplo, tem passado. As vicissitudes políticas e as ideologias de governo não priorizaram a educação nas últimas três décadas, deixando um saldo nada abonador para o país. Um dos aspectos mais constrangedores e delicados tem sido o lugar ao qual foi relegada a pessoa do educador: um lugar subalterno, que ele nunca teve e que nunca mereceu, sendo que o professor sempre foi um dos pilares da comunidade. Atualmente, ele é um cidadão muitas vezes desinformado, mal formado e mal pago, nada influente na sociedade. Ser professor é uma das últimas coisas que um jovem quer ser, profissionalmente. Além disso, com a diminuição e cortes de verba para a educação, o acervo patrimonial das escolas foi descuidado e destroçado e quase nada de novo foi feito. O tempo de permanência na escola foi diminuindo em função do excesso de crianças x escassez de salas de aula e a má educação passou a existir onde outrora havia educação. Creio que acabo de pintar um quadro de violência exercida sobre todo o sistema educacional formal.

Examinando-se detalhadamente esta situação, encontram-se alguns fatores que parecem concorrer para ela, a saber:

\section{Fatores de ordem do conhecimento}

Parece que a sociedade como um todo desfruta de um grau de conhecimento, promovido pelos incomensuráveis progressos da ciência e tecnologia que a escola tem tido muita dificuldade em acompanhar, criando um intervalo cultural muito grande entre aquilo que se aprende na escola e o que se aprende fora dela, pelos meios de comunicação, principalmente a televisão. Mas não só de ciência e tecnologia carecem as escolas, mas de todos os novos aportes que as ciências humanas e da saúde podem lhe dar: Sobretudo a pedagogia e as ciências da educação, contribuindo com uma metodologia mais moderna e diversificada, apropriada para as distintas populações. Já em 1986, ao abrir a conferenciada OMS, S. (19) dizia que há muito mais conhecimento sobre saúde e educação no mundo do que aquele que é posto à disposição da infância, principalmente na América Latina. Aqui caberia examinar-se a importância das contribuições que a Psicanálise tem dado e poderia intensificar, principalmente com a abertura das suas pesquisas para a comunidade. É reconhecido por todos a importância dos estudos sobre o psiquismo fetal, sobre as relações mãe $\mathrm{x}$ bebê e as formas como o ambiente continente e afetuoso contribuem para o bom desenvolvimento das crianças. Em suma, creio que a Psicanálise pode contribuir de duas formas, principalmente, para o desenvolvimento dos fatores da ordem do conhecimento: pondo em comum o acervo de suas descobertas e abrindo possibilidades cada vez mais amplas de acesso à população ao próprio tratamento psicanalítico. 


\section{Fatores de ordem política}

Com a predominância das mentalidades empresariais há uma tendência para que as escolas sejam vistas como empresas nas quais a relação custo x benefício é uma das prioritárias. Fins comerciais prevalecem sobre fins educativos. Parece que há falta de uma vontade política de encarar a educação na sua forma específica, e não como uma mercadoria. Essa mentalidade mercantilista tem tido alcances tão amplos que chegam a influir na filosofia educacional das escolas e no conteúdo programático das disciplinas ministradas. É bem conhecida a propaganda que certas escolas de primeiro grau fazem de que já começam a preparar as crianças para o vestibular, ou seja, para a guerra da entrada nas Universidades.

\section{Fatores relativos ao afastamento e descompromisso da comunidade para com o processo educacional}

As famílias não se consideram diretamente implicadas e responsáveis pela educação formal. Nas regiões mais carentes, ainda é comum a mentalidade de que a escola é algo que o governo dá para a população e não um direito desta. Muito recentemente, com o surgimento da mentalidade dos "direitos do consumidor" a comunidade vem acordando para a qualidade daquilo que lhe é oferecido, inclusive a educação formal. Também a ecologia com os seus apelos à preservação do meio ambiente e muitas ONGs, têm dado uma contribuição decisiva para a modificação deste quadro.

Este é um quadro penoso de ser pintado, mas ele é verdadeiro numa grande parte do meu país e, possivelmente, em outras partes também da América Latina. É claro que em todos os lugares há "ilhas de excelência" nas quais políticos, educadores e famílias têm se unido na busca de melhores dias para a educação. No Brasil temos visto a comunidade, através de seus jovens principalmente, tomar a si os programas de alfabetização de adultos, de manutenção de crianças carentes na escola, de amparo à terceira idade, entre outros. Também o Ministério da Educação, através de seus técnicos, tem procurado trazer par as salas de aula novos recursos metodológicos de vídeo, áudio e som são empregados, e de pesquisas auxiliares. Tudo isso aponta para um futuro mais promissor e menos violento.

Tendo contextualizado o ambiente no qual se dá a educação formal hoje, fica mais fácil a compreensão e até a aceitação de atitudes anti-pedagógicas e violentas como as que muitas vezes temos presenciado. $\mathrm{O}$ professor tornou-se um profissional carente de apoio e compreensão, necessitando de uma reciclagem profissional para que se ponha no caminho da modernidade.

Larson (1994) num artigo para a School Psychology Review, nos fala de um programa para a prevenção da violência nas escolas, chamado Think First, no qual são contemplados aspectos de prevenção primária, secundária e terciária com diferentes populações de estudantes e nos quais as famílias devem ser sempre incluídas. Embora o referencial teórico que embase este programa seja o behaviorista cognitivo, combinado com o senso comum, como eles mesmos o dizem, o programa tem o grande mérito de trazer a discussão do problema para dentro da escola e, procura lidar com as pessoas implicadas no processo, como elas realmente são, e não, aplicando métodos oficiais, criados em outros ambientes idealizados, como muitas vezes acontece.

Miller (1994), na mesma revista, faz uma Revisão Crítica desses programas de prevenção, nos quais se inclui o Think First, começando por perguntar "Será que a violência na escola é mesmo um problema maior?" (p.257, a tradução é minha). É muito difícil responder a essa questão porque não há um consenso sobre o que seja violento na escola. Ora a violência é superestimada pela mídia, por exemplo, ora ela é subestimada pelos próprios professores que temem ser considerados 
inadequados, ou serem contra atacados. Esta é uma realidade também no Brasil onde não se anotam mais as faltas de disciplina ou os atos de violência física ou verbal cometidos pelos alunos, em nome dos "direitos da criança". A autora faz uma relação das causas que, a seu ver, contribuem para a violência na juventude e arrola questões pessoais, familiares, sociais, escolares e psicossociais. Entre as pessoais estariam aquelas próprias das personalidades imaturas, das mentes primitivas que não conseguem elaborar aquilo que a Psicanálise configura como o "conflito edipiano", e que já foi explorado na primeira parte desta comunicação. Geralmente, há uma combinação de dificuldades familiares com as pessoais: pais em conflito pessoal dificilmente sabem lidar com seus filhos. Do ponto de vista das causas escolares, a autora arrola dois tipos de causas: as que se prendem ao ambiente físico da escola inadequado, pouco atraente - e ao entrosamento escola x comunidade, e as que se prendem à filosofia educacional: regras estritas e autocráticas, privilegiar notas e não conteúdos, pouca escolha curricular. Também condições psicossociais próprias do âmbito escolar são apontadas: relacionamento pobre entre professor e alunos, os alunos sentem-se desconsiderados e/ou injustificados. Quanto às causas sociais, aponta as clássicas: pobreza, desemprego, nível sóciocultural baixo e discriminação racial.

O papel prioritário do profissional da Psicologia e da Psicanálise na escola, eu diria, seria o de criar um ambiente de apoio "nurturing" - que proteja a criança da violência pessoal e ambiental e promova o seu desenvolvimento e bem-estar.

Concluindo o seu artigo, Miller aponta cinco pontos segundos os quais as escolas deveriam se orientar para lidar com esses aspectos da violência. Comentarei aqui apenas dois deles, que me parecem mais pertinentes ao tom deste trabalho. Em primeiro lugar, encara a segurança na escola como o fruto criativo de um processo de colaboração de todo o grupo implicado na educação. A meta é fazer com que todos se sintam responsáveis. O segundo diz respeito à necessidade e à importância de se criar políticas sensíveis a individualização - não há soluções universais. A escola, a psicologia e a Psicanálise, neste particular, podem dar-se as mãos na tentativa de criarem programas de atendimento aos alunos, mais específicos, mais apropriados a características específicas de certas personalidades e/ou culturas. Pesquisas mostram que um bom programa deve ser: a) adaptado a crianças específicas e para escolas, famílias e comunidades características, b) incluir mudanças multissistêmicas e c) estar baseado no respeito às diversidades e na apreciação das forças e diferenças culturais.

\section{Referências}

Andrade, A. N. (1998). A criança na sociedade contemporânea: do "ainda não" ao cidadão em exercício, Psicologia: Reflexão e Critica, 11(1): 161-174, Porto Alegre.

Bion, W. (1962-3). O aprender com a experiência, capo 26,27,28 in Elementos de Psicanálise, trad. Jayme Salomão, Rio de Janeiro: Zahar, 1966.

Caper, R. (1996). O brincar, a experimentação e a criatividade, Livro Anual de Psicanálise, XII, 129-138, São Paulo: Ed.Escuta.

Carvalho, R. M. L. L. (1992). Psicoterapia Psicanalítica com crianças e adolescentes institucionalizados, Tese de doutoramento, UNICAMP.

Ferreira, A. B. de H. (1986). Dicionário da Língua Portuguesa,2a edição, Rio de Janeiro: Nova 
Fronteira.

Faimberg, H. (1996). A escuta da escuta, Livro Anual de Psicanálise, XII, 107-116, São Paulo: Ed. Escuta.

Freud, S. (1917b). Conferências Introdutórias sobre Psicanálise n. XXIII: Os caminhos da Formação de Sintomas, Edição Standard Brasileira das Obras Psicológicas Completas de Sigmund Freud. vol.XVI, Rio de Janeiro: Imago, 1976.

Freud, S. (1919a). Uma criança é espancada, Edição Standard Brasileira das Obras Psicológicas Completas de Sigmund Freud. vol. XVII, Rio de Janeiro: Imago, 1976.

Freud, S. (1919b). Prefácio a Ritual: Estudos Psicanalíticos de Reik, Edição Standard Brasileira das Obras Psicológicas Completas de Sigmund Freud, vol. XVII, Rio de Janeiro: Imago, 1976.

Freud, S. (1940[1938]). Esboço de Psicanálise, Edição Standard Brasileira das Obras Psicológicas Completas de Sigmund Freud. vol. XXIII, Rio de Janeiro: Imago, 1976.

Klein, M. Notas sobre alguns mecanismos esquisóides

(1929). The development of a child. in The Writings of Melanie Klein, vol. I

(1931). The theory $h$ intellectual onhobotion

(1932). Psicanálise da Criança, capo 9, trad. De Pola Civelli, in The Writings of Melanie Klein, vol. II, São Paulo: Mestre Jou, 1969.

Larson, J. (1994). Violence Prevention in the schools: a review of selected programs and procedures, School Psychology Review, 1994, 23(2),151-164, NASP.

Miller, G. E. (1994). School Violence Miniseries: impressions and implications, School Psychology Review, 23(2),257-261, NASP.

Segall, H. (1982). Uma abordagem Psicanalítica da Estética, Em: A obra de Hanna Segall, Rio de Janeiro: Imago.

Silva, Ma. C. P. (1994). A Paixão de Formar: da Psicanálise à Educação, Porto Alegre, Artes Médicas.

S/n (1998). Adolescência e Violência, projeto de tese de doutoramento, Campinas, UNICAMP.

Recebido em janeiro 1999.

Encaminhado para revisores em janeiro 1999.

Reencaminhado em fevereiro 1999.

Aprovado em março 1999. 